\title{
Rev Bras Hematol Hemoter. 2012;34(2)
}

The following figure replaces Figure 1 incorrectly published in the Letter to editor "Survival of patients diagnosed with subsets of lymphoid neoplasms and acute myeloid leukemia from 2000 to 2010 in the Vale do Paraíba, State of São Paulo: are we going the right way?" published in Rev Bras Hematol Hemoter. 2012;34(2):168-71

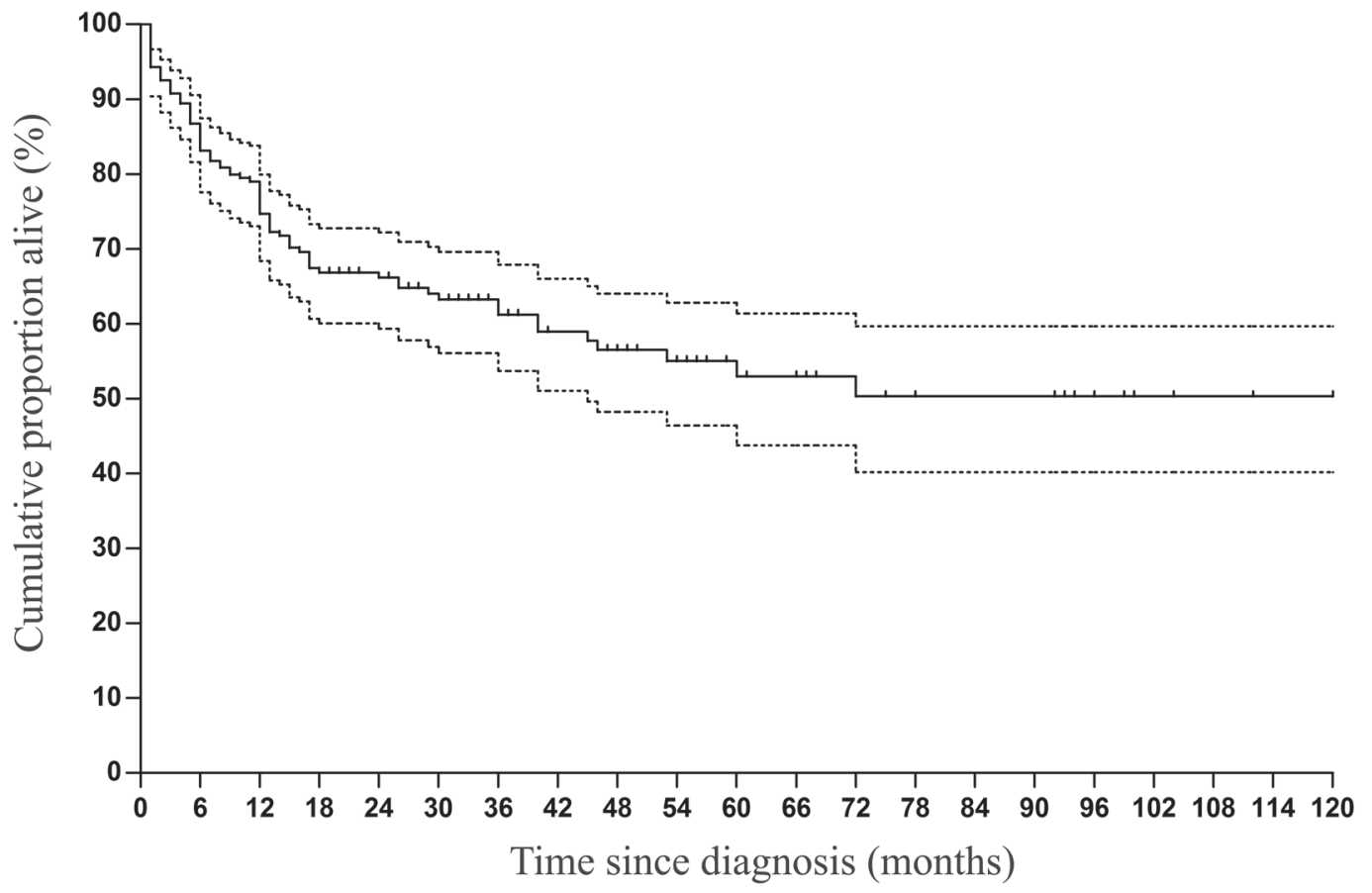

